\title{
Damage detection in a post tensioned concrete beam - experimental
}

investigation

M.P. Limongelli

Politecnico di Milano, Department of Architecture, Built Environment and Construction Engineering

D. Siegert, E. Merliot, J. Waeytens, F. Bourquin

Université Paris-Est, IFSTTAR, France

R. Vidal

ADVITAM, VINCI, France

V. Le Corvec

NECS, France

Gueguen, L. M. Cottineau

Université LUNAM, IFSTTAR, Nantes, France

ABSTRACT: The paper deals with the results of an experimental campaign carried out on a post tensioned concrete beam with the aim of investigating the possibility to detect early warning signs of deterioration based on static and/or dynamic tests. The beam was tested in several configurations aimed to reproduce 5 different phases of the 'life' of the beam: in the original undamaged state, under increasing loss of tension in the post tensioning cables, during and after the formation of cracks at mid span, after a strengthening intervention carried out by means of a second tension cable, during and after the formation of further cracks on the strengthened beam. Responses of the beam were measured by an extensive set of instruments consisting of accelerometers, inclinometers, displacement transducers, strain gauges and optical fibers. In this paper data from accelerometers and displacement transducers have been exploited. The paper presents the test program and the dynamic 
characterization of the beam in the different damage scenarios in terms of the first modal frequency, identified from dynamic tests and of the bending stiffness monitored during static tests.

\section{INTRODUCTION}

Due to aging, to aggressive environment and/or to increasing service loads, a large part of the existing bridges all over the world have been deteriorating and require inspections to assess their health state. One of the main causes of deterioration of prestressed concrete beams is the corrosion of the strands that may cause cracking of concrete and the following opening and closing ('breathing') of the cracks during the passage of heavy vehicles. The early stage detection of cracks and/or of tension losses can thus be strategic to improve the structural safety. Access to strand anchorage and retensioning of strands is often difficult or even impossible hence the assessment of the structural performance is often carried out based on indirect features recovered from response to vibrations. Static and dynamic non destructive methods can be used for this purpose and extensive experimental and numerical studies have been carried out on the subject. All the investigations show that the cracking of the concrete section leads to a global reduction of stiffness and to a local increase of curvature that can be reliably detected basing on the structural response to vibrations (provided the fault induces measurable variations of these features). On the contrary, the effect of the detensioning of the cables and of the 'breathing' cracks on dynamic parameters such as modal frequencies, are reported to be quite difficult to identify [1]. In their paper published in 1986, Kato and Shimada [2] point out that a decrease of the natural frequencies occurs at the formation of cracks but, up to the yielding of the prestressing wires, variations are almost negligible due to the closing of cracks. This is confirmed in references [3], [4] reporting about experimental tests carried out on the three span prestressed Z24 bridge in Switzerland: the variation of modal parameters are very small before the yielding of reinforcement. The possibility to detect prestress losses from variations of modal frequencies was investigated also in the paper by Saiidi et al. [5] who concluded that the 
variations of frequencies induced by changes in the prestress in practical ranges are too small to allow a reliable estimation of the prestress losses. Similar conclusions are reported in references [7], [8] and [9] where the variations of the modal frequencies with corrosion are experimentally assessed for prestressed concrete beams. In all these studies very small variations of the modal frequencies are reported for low to medium level of corrosion induced cracking of the concrete.

Despite the above interest, very few studies deal with the correlation between the results of static and dynamic tests in different health conditions of the structure.

This paper presents the results of an experimental campaign carried out on a prestressed concrete beam. The tests were carried out in the realm of the project SIPRIS (Systèmes Intelligents pour la Prévention des Risques Structurels), aimed to develop intelligent systems for the prevention of structural risk related to the aging of large infrastructures.

The specimen was tested in several configurations aimed to reproduce several different phases of the 'life' of the beam: in the original undamaged state, under an increasing loss of tension in the cables, during and after cracking induced by a point load, after a strengthening intervention, after new cracking of the 'repaired' beam. Damage was introduced in a controlled way by means of threepoint static bending tests. The transverse point loads were applied at several different sections along the beam axis. Before and after each static test, the dynamical response of the beam was measured under sine-sweep and impact tests by an extensive set of accelerometers deployed along the beam axis. The availability of both static and dynamic tests allows to investigate and compare their effectiveness to detect damages in the tensioned beam and to reliably identify the evolution of damage. This paper discusses the tests program and some results relevant to the dynamic characterization of the beam in the different phases.

One of the aim of the experimental campaign was to investigate if low-cost networks of sensors with for example one single accelerometer and one displacement transducer could allow a correct characterization of the beam in different phases (undamaged, cracked, repaired). 
To this aim the variation of the first modal frequency during the whole test sequence was studied to investigate the sensitivity of this parameter to both the cracking of the concrete section and the tension in the cables and also to compare results given by different types of experimental tests and setups described in the following section. Results of the static tests were also presented using data from only one of the displacement sensors placed on the beam. The correlation between the results of the static and dynamic tests is also carried out by comparing results related to the different phases of testing in terms of the correlation between the first modal frequency and the bending stiffness of the beam.

\section{EXPERIMENTAL TESTS}

\subsection{Tested beam}

A reduced scale model of a VIPP (Viaducs à travées Indépendantes à Poutres Précontraintes Prestressed girder beam deck with independent spans) post-tensioned beam was designed to test the effectiveness of different experimental techniques and to detect early signs of deterioration. Generally, a loss of the tension force in the cables is characterized by the occurrence of corrosion affecting a cable section. The reduction of the section leads to the breaking of the strands and to the reduction of the prestressing at the corroded section. The anchorage of the strands at the sides of the corroded area limits the diffusion of the phenomenon to a few tens of centimeters. The macroscopic effect of such a fault is a significant drop in stiffness - hence in the natural frequency - and a localized increase of curvature. In these cases the section is cracked, and probably the fault is visible on the surface during an inspection. When the crack is not very important, it is not visible from the outside and stiffness does not exhibit sensible changes. The most sensitive period for the beam is the transition between the two states, with a significant drop in preload, allowing the opening and reclosing of the cracks during the passage of a large convoy. The objective of the SIPRIS project was 
to investigate different experimental means capable to reveal the existence of such a mechanism.

The scaled model was designed to be representative of actual VIPP girder beams of bridge decks but some constraint were identified for its construction. Specifically: to have a light weight to facilitate handling and to have Service Limit Load (SLL) compatible with the performances of the testing device. The total span length of $8 \mathrm{~m}$ was the minimum length allowing the use of standard prestressing techniques. These constraints led to the deployment of total number of 3 tendons $(2$ straight cables L1 placed at the bottom of the beam and one parabolic cable L2 deployed as shown in Errore. L'origine riferimento non è stata trovata.) instead of the 11 cables present in the original VIPP beam.
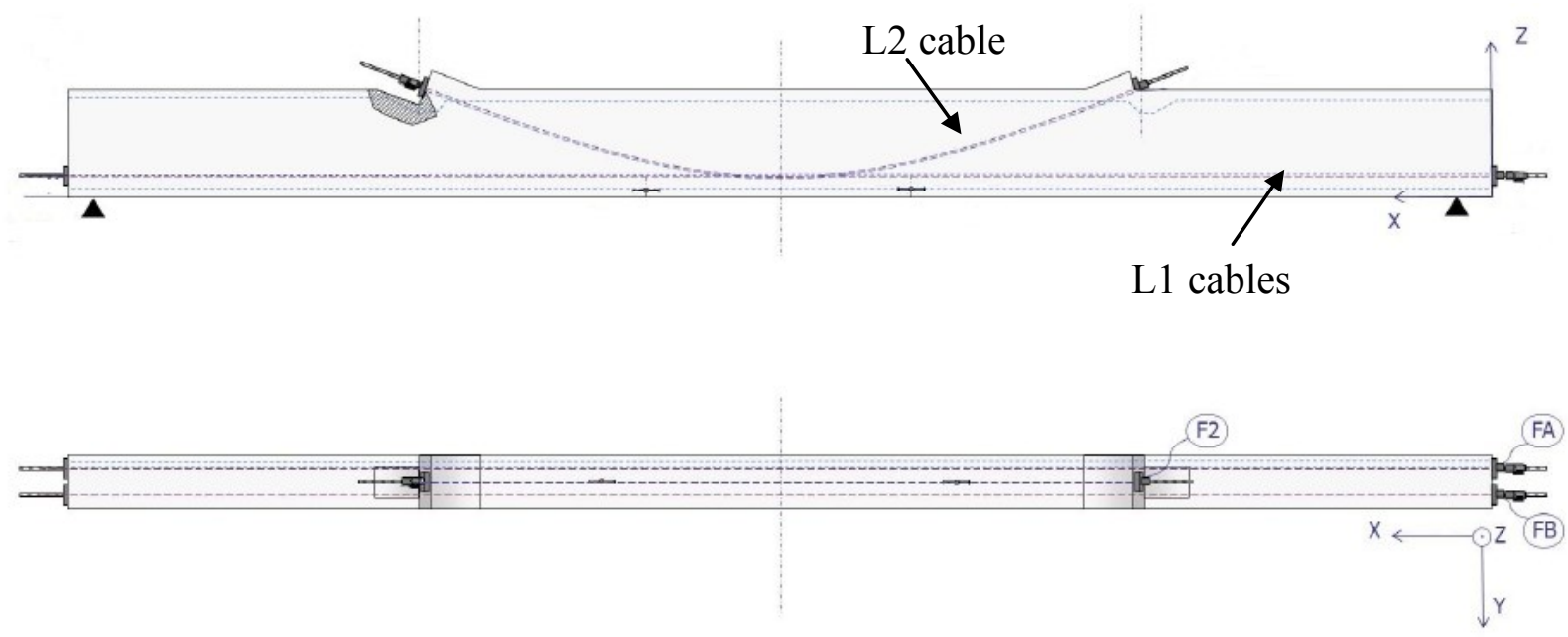

Figure 1: The tested beam: post-tensioned cables

Furthermore individually coated strand were used, each made of one single strand tensioned at the minimum force value to allow the opening and closing of the cracks. The tendons were produced with sheath injected with grease and were travelling one by one into the beam; they were not injected.

During the tests the beam, with a cross section of $30 \mathrm{~cm} x 60 \mathrm{~cm}$ (see Figure 2), was simply supported at the ends across a clear effective span of $7.9 \mathrm{~m}$ by concrete blocks via two neoprene bearing pads $300 \times 160 \times 30 \mathrm{~mm}^{3}$ reinforced with one steel plate $300 \times 160 \times 5 \mathrm{~mm}^{3}$. The boundary conditions were chosen to reproduce the 'real world' condition of VIPP beams which are simply supported at 
the ends.

The properties of the concrete recovered from tests on the material are: strength 33MPa, Youngs modulus $29 \mathrm{GPa}$. The ultimate tensile strength of the tendons was $1860 \mathrm{MPa}$, the minimum breaking load is $270 \mathrm{kN}$.

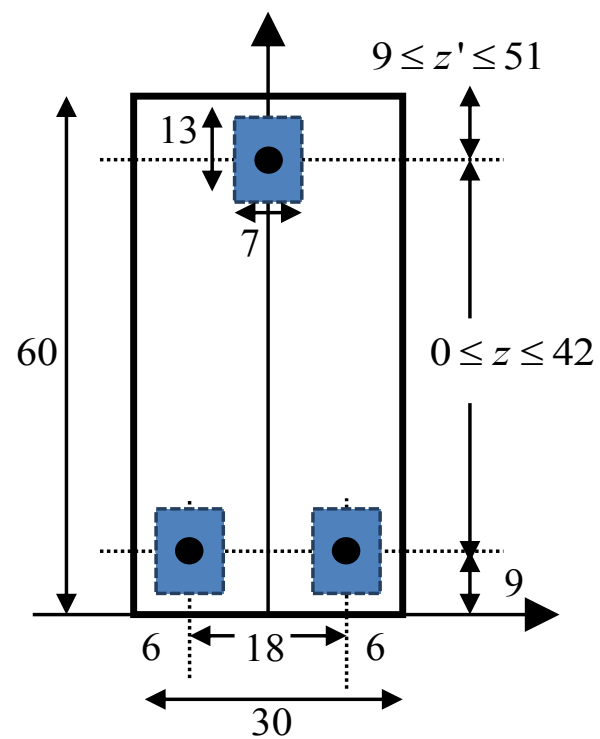

Figure 2: The tested beam: cross section. Measures in $\mathrm{cm}$.

\subsection{Experimental setup}

Both three point bending static tests, sine sweep and hammer dynamic tests were carried out on the beam. The loads for the static tests were generated by a hydraulic jack of $100 \mathrm{kN}$ capacity and transferred to the beam via a steel plate (see Figure 3). 


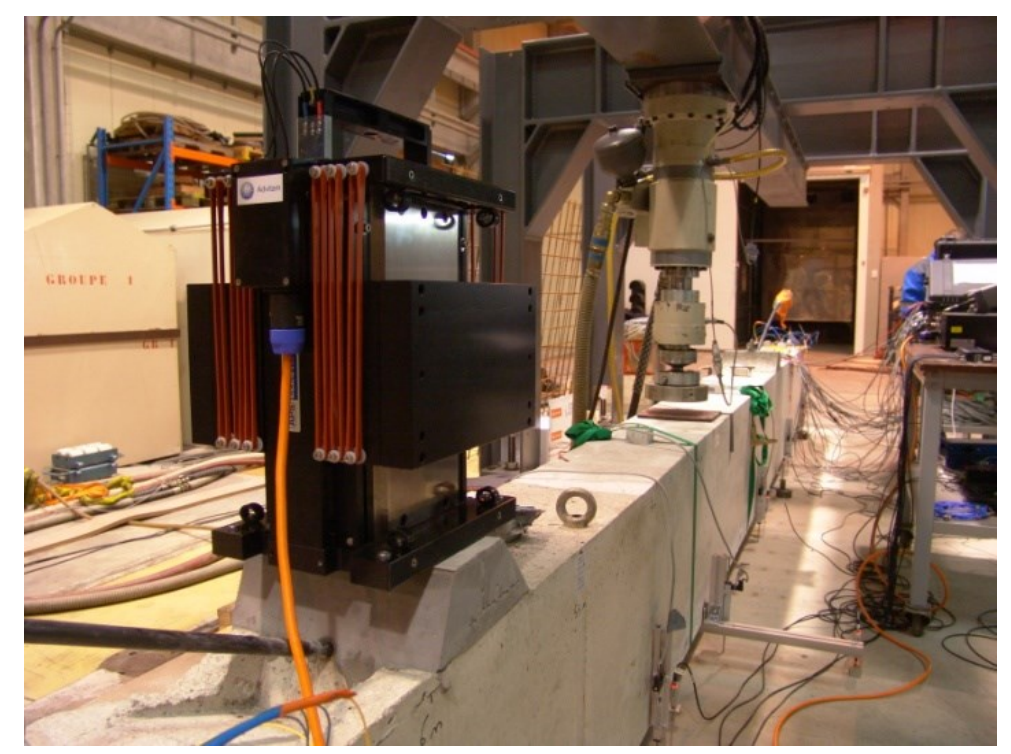

Figure 3: The specimen on the test bench with the shaker and the hydraulic jack.

The hammer tests were performed using a hammer Kiag Swiss $906 \mathrm{~B}$ with a mass of $9 \mathrm{~kg}$ mass to impact the beam. Sine sweep tests were performed using a shaker APS 400 Electro-seis shaker with a mass of $70 \mathrm{~kg}$.

An extensive set of accelerometers and displacement transducers was deployed on the beam to measure its response: labels and locations of the sensors are reported in Figure 4 and Figure 5.

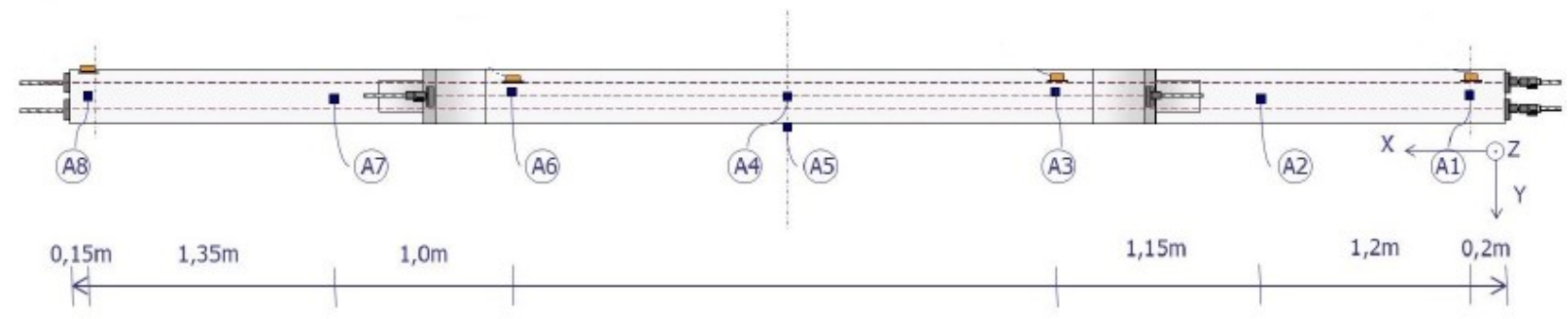

Figure 4: Location of accelerometers (A1 to A8)
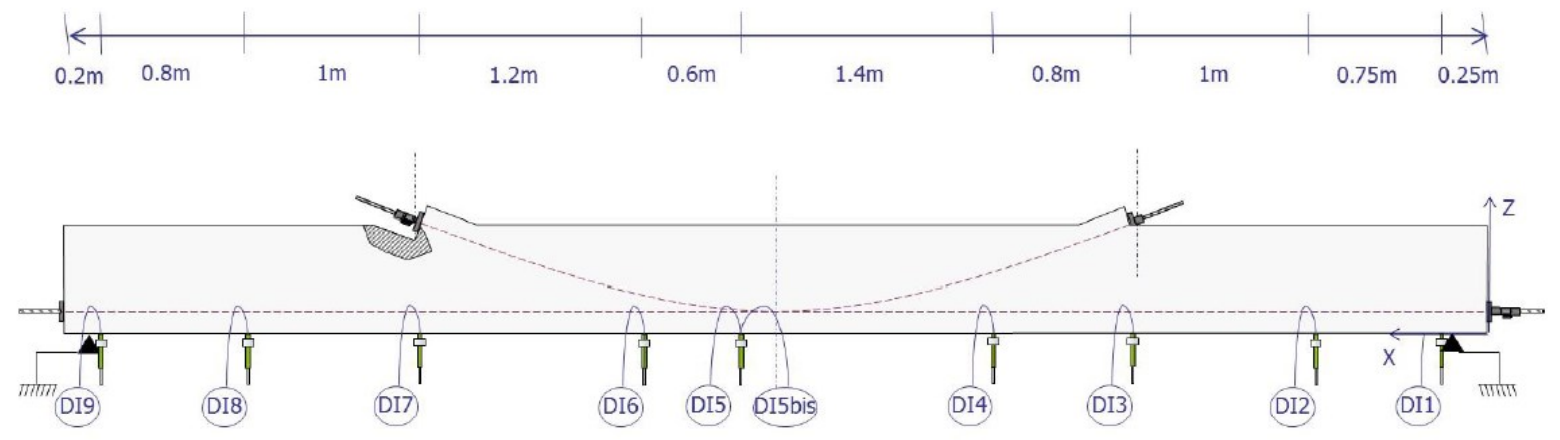
It must be noted that the displacement transducers DI1 to DI4 and DI6 to DI9 were deployed on the bottom left side of the beam. On the section located at $3.8 \mathrm{~m}$ from the left support two displacement transducers where deployed in order to measure possible rotations of the beam around its longitudinal axis (see Figure 6).

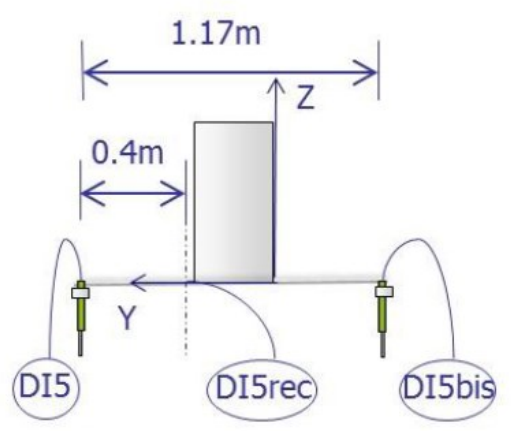

Figure 6: Location displacement transducers at mid-span

Accelerations were measured at a sampling rate of $200 \mathrm{~Hz}$ with analog accelerometers Silicon design 2210 with a sensitivity of $(800 \mathrm{mV} / \mathrm{g})$ placed vertically at the top of the beam. Displacements were measured by Atek $100 \mathrm{~mm}$ linear potentiometers. After the formation of the first cracks in phase 2, some crack opening displacement (COD) gauges were deployed at their locations in order to measure their width during the following loading cycles. Four load cells were used to measure the force in the 3 cables ( $2 \mathrm{~L} 1$ and L2) and the point load applied during the static tests. The acquisition system was a National Instrument 24 bit analogical input modules 9239 system digitizing the eight accelerometers (A1-A8) in 24 bits with two 9239 cards, the temperature with a 9211 card and K type thermocouples, the eight Omega strain sensors (P1-P8) where digitized by a 9237 card in 24 bits and the three rotations (I1-I3) and seven displacements (D1-D7) in 16 bits with a 9205 card. 


\subsection{Test procedure}

In order to investigate the effect of cracks and of the tension loadsin the cables on the dynamic characteristics, both static and dynamic tests were performed. The beam was initially tested in its undamaged configuration and afterwards a de-tensioning of the bottom cables (L1) was performed. Cracking was subsequently induced by applying a concentrated load at mid-span of the beam. Afterwards the point load was moved to other locations in order to simulate the effect of a moving vehicle and to study its effect on the opening and closing of the cracks. A second post-tensioning parabolic cable (L2), aimed to simulate the effect of a retrofitting intervention, was then tensioned and the beam was again cracked and loaded with a concentrated load at different sections along its axis in order to compare the behavior of the damaged and the 'repaired' beams. In Table 4 the detailed list of the static and dynamic tests carried out on the beam is reported. In the table ' $\mathrm{B}$ ' denotes sine sweep tests, ' $\mathrm{S}$ ' indicates static tests and ' $\mathrm{M}$ ' is used for hammer tests.

After each static test, a series of dynamic tests (sine sweeps and hammer tests) were performed to follow the evolution of the dynamic parameters of the specimen. Specifically the test procedure was organized into 5 phases as follows:

- phase 0 : tests on the original undamaged beam;

- phase 1: de-tensioning of the bottom cables;

- phase 2: cracking at the mid-span and loading in three points bending;

- phase 3: tensioning of the second cable (parabolic cable L2) and loading of the 'repaired' beam;

- phase 4: cracking at $1 / 3$ of the span length with a point load and loading at different sections to simulate the effect of a moving load.

\subsection{Static tests}

Three points static bending tests were carried out to characterize the specimen and also, in phases 2 and 4, to induce cracking. The characterization tests were performed by applying a concentrat- 
ed load up to $10 \mathrm{kN}$ at different sections and specifically at mid-span, at $1 / 3$ of the clear length $L$ from the left support and at L/8 from the left support, as specified in Table 4.

During phase 2 and phase 4, subsequent loading cycles with increasing values of the maximum deflection $(3,4$, and $5 \mathrm{~mm})$ were imposed to crack the beam. Specifically cracking at midspan occurred during tests S63 and S73, cracking at L/3 occurred during test S122. The cracked pattern at midspan after test $\mathrm{S} 73$ is reported in Figure 7.

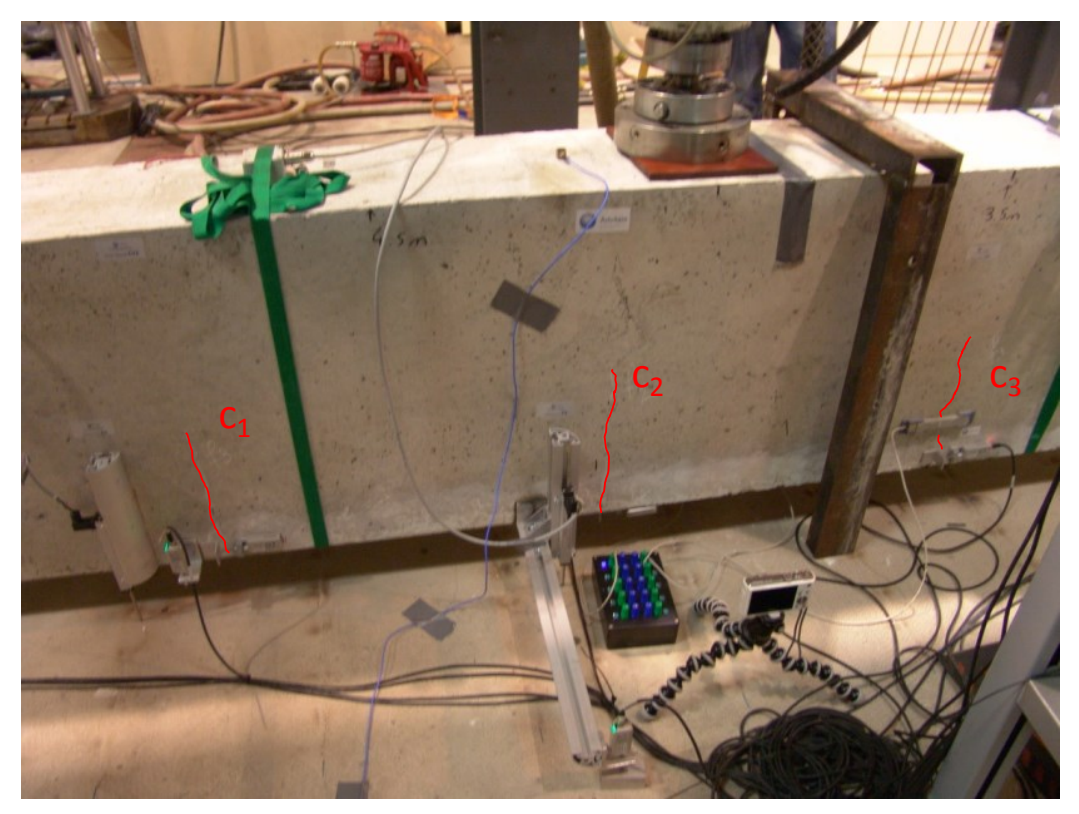

Figure 7: Cracked pattern of the beam during phase 2

\subsection{Dynamic tests}

Before and after each static test a number of dynamic tests were carried out to estimate the dynamic characteristics of the beam. Both sine-sweeps (B) and hammer (M) tests were performed and are described in Table 1. Most of the sine-sweeps were performed with the shaker placed on the beam at about 2/3L from the left support. A limited number of tests, specified in Table 4, were carried out with different shaker locations, in order to study the effect of the position of the shaker mass on the dynamic characteristics of the beam.

Linear sweep tests on 2 seconds were performed both in small frequency ranges $(5-10 \mathrm{~Hz} ; 10$ - 
$20 \mathrm{~Hz} ; 20-40 \mathrm{~Hz} ; 40-80 \mathrm{~Hz}, 80-160 \mathrm{~Hz})$ and in the whole frequency range $(5-200 \mathrm{~Hz})$. Logarithmic sweep tests were carried out over 2 minutes on the frequency range (5-200 Hz). Due to the different length of the frequency range considered for the several sine sweep tests, all carried out during 2 minutes, different sweep rates were used. The (constant) sweep rate for a the linear sweep tests over a duration $T_{\mathrm{d}}$ covering a frequency range from $f_{0}$ to $f_{\mathrm{f}}$, is defined by $\alpha=\left(f_{f}-f_{0}\right) / T_{d}$. It was lower for the tests in smaller frequency ranges: $0.0833 \mathrm{~Hz} / \mathrm{s}$ for the linear tests in the range $10-20 \mathrm{~Hz}$ and $1.625 \mathrm{~Hz} / \mathrm{s}$ for the linear sweep tests in the range $5-200 \mathrm{~Hz}$. For the logarithmic sweep tests the sweep rate is not constant during the test and is given by $\alpha=f_{o} \cdot S \cdot 2^{S \cdot t}$ being $S=\left\lfloor\log _{2}\left(f_{f}\right)-\log _{2}\left(f_{o}\right)\right] / T_{d}$ over a duration $T_{\mathrm{d}}$. For the tests reported herein, when the frequency of the excitation reaches the first modal frequency (around $13.8 \mathrm{~Hz}$ for the undamaged beam) the sweep rate is: $\alpha=0.61 \mathrm{~Hz} / \mathrm{s}$ that is lower with respect to the sweep rate of the linear sweep in the same frequency range $(5-200 \mathrm{~Hz})$. As will be shown in the following, the different values of the sweep rates influence the value estimated for the first modal frequency.

Responses to the sine sweep tests were analyzed using standard technique based on Fourier spectral analysis and allowed to detect the first 3 modes of the beam. Specifically, for the sinesweep tests, the values of the modal frequencies were computed by peak-picking of the frequency response functions. For the hammer tests, since the input signals was not always correctly recorded due to a malfunctioning, the values of the first three modal frequencies were computed assuming the input unknown and using Frequency Domain Decomposition (FDD) and the Stochastic Subspace Identification (SSI) methods, implemented in the software package ARTeMIS [9].

\section{ANALYSIS OF DAMAGE}

Herein the evolution of damage during the different phases of tests is investigated through the variations of the first modal frequency retrieved from different types of tests. The second and 
third modal frequencies of the beam were scarcely excited during several hammer tests due to the hammer used for the tests that concentrated most of the energy at lower frequency in order to properly excite the first mode of the structure. The location of the shaker in some tests hampered the correct identification of the second and/or third more from sine sweep tests as well. Furthermore, as will be shown in the following section 3.1.6, the second bending mode is much less sensitive to the damage induced at midspan with respect to the first mode due to the presence of its node in that section. The most complete and reliable set of data available is thus the one relevant to the first modal frequency and is the one used herein to investigate the evolution of damage in the different phases of tests. This parameter, as will be shown, is able to correctly detect damage provided the analysis of the experimental responses are carried out taking into account the possible influence of the test conditions (e.g. the distribution of masses of the type of tests: sine-sweeps vs. hammer tests).

\subsection{Evolution of the first modal frequency with damage}

The evolution of the first modal frequency during the test sequence is reported in Figure 8: . The values identified are the same whatever the sensor (A1 to A8). The shift between the values of frequencies estimated from the different sine-sweep tests depends on the different sweep rate and, consistently with the theoretical findings [12]-[13], the computed value increases with the sweep rate. In any case it must be noted that there is a systematic shift between the values of frequency calculated from the different sine sweep tests and from the hammer tests confirming that such differences are mainly due to the type of test employed to estimate the modal frequency. 


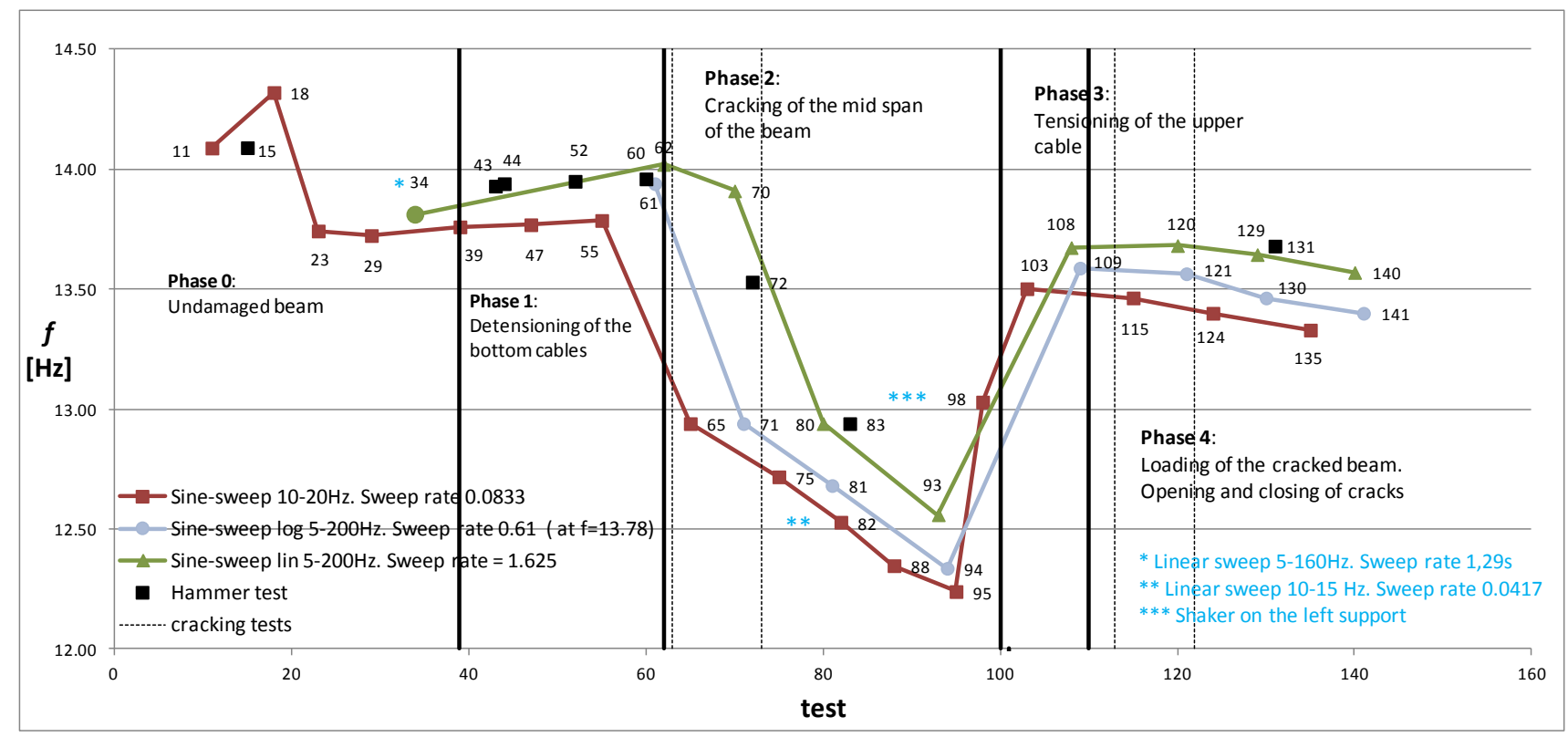

Figure 8: Evolution of the first modal frequency during the test sequence.

\subsubsection{Phase 0. Undamaged beam}

In phase $\mathbf{0}$ no cracks were observed after the application of the concentrated loads, consistently with the fact that the values estimated for the internal moments due to the applied loads of $10 \mathrm{kN}$ were lower than the theoretical estimate of the SLL (Service Limit Load) of the beam. Nevertheless the values of the first modal frequency identified from the results of the dynamic tests show slight changes between one test and the following from test 10 to test 32 . Such variations can be ascribed partly to the variation of the mass distribution due to the change in the position of the shaker (L/4L, $\mathrm{L} / 8, \mathrm{~L} / 2, \mathrm{~L} / 8,2 \mathrm{~L} / 3$ from the left support) during the different tests (see Table 1 ). In order to verify this explanation the Rayleigh ratio [6] was calculated for the different positions $\mathrm{x}_{\mathrm{S}}$ of the shaker mass $m_{\mathrm{S}}=70 \mathrm{~kg}$.

$$
\left(f_{0}+\Delta f\right)^{2}=\frac{1}{4 \pi^{2}} \frac{\int_{0}^{L} E I v^{\prime \prime}(x)^{2} d x}{\int_{0}^{L} \mu \nu(x)^{2} d x+m_{S} v\left(x_{S}\right)}
$$

where $\mu$ is the beam mass per unit length and $v(x)=\sin (n \pi x / L)$ is the modal shape related to the $n$-th eigenvalue, $f_{0}$ is the value of the first modal frequency of the beam when the shaker is not 
placed on the beam and $\Delta f$ is the variation of the frequency induced by the mass $m_{S}$.

Assuming small frequency variations (that is neglecting $\Delta f^{2}$ with respect to the other terms), equation (1) gives the relative variation of frequency due to the mass $m_{\mathrm{S}}$ with respect to the value $f_{0}$ :

$$
\frac{\Delta f}{f_{0}}=\frac{m_{S}}{M} \sin ^{2}\left(\frac{n \pi x_{S}}{L}\right)
$$

The value of the first modal frequency of the beam without the mass of the shaker $f_{0}$ was not measured. In order to compare the variations $\Delta f$ given by equation (2) with those computed from the sine sweep tests it is assumed that the original value is the one given by equation (2) for test B18 that is $f=14.33 \mathrm{~Hz}$. The comparison of the value reported in Table 1 show that the values of $\Delta f / f_{0}$ follow the same trend but the variations computed from identified frequencies are higher. This means that part of the variation can be justified by the change in the mass distribution but other phenomena occur as well that modify the values of the first modal frequency. A possible explanation could be the presence of some microcracks close to the midspan of the beam that were not engaged when the position of the shaker was at L/8 close to the left support of the beam, but opened when the shaker was moved to $\mathrm{L} / 2$ and $2 / 3 \mathrm{~L}$..

Table 1. Variations of the first modal frequency with the position of the shaker

\begin{tabular}{|c|c|c|c|c|c|}
\hline $\mathrm{Te}$ & & B11 & B18 & B23 & B29 \\
\hline Position of & he shaker & $\mathrm{L} / 4$ & $\mathrm{~L} / 8$ & $\mathrm{~L} / 2$ & $2 \mathrm{~L} / 3$ \\
\hline \multirow{2}{*}{$\Delta f / f_{0} \cdot 100$} & Rayleigh & 1.1 & 0.06 & 2.0 & 1.7 \\
\hline & Identified & 1.7 & 0.06 & 4.2 & 4.0 \\
\hline
\end{tabular}

\subsubsection{Phase 1. Detensioning of bottom cables}

In phase 1 the tension in the cables $N$ was gradually reduced by releasing separately each of the two cables from about $120 \mathrm{kN}$ to about $40 \mathrm{kN}$ each. As shown in Figure 8: , the first modal frequency 
stays pretty constant at the decrease of the tension in the bottom cables, whatever the type of dynamic test. It must be noted that during test 34 a lower sweep rate was used with respect to the other linear sweeps hence a corresponding lower value of frequency was estimated. The small influence on the modal frequencies of the axial load $N$ in the cables is consistent with the findings of several experimental tests carried out on prestressed beams with straight eccentric cables [2], [4], [8] and can be explained considering a very simple mechanical model of a supported beam of mass per unit length $m$, length $L$, subjected to a prestress force $N$. The $n$-th natural frequency of vibration for a beam with non injected cables is given by the following relationship [11]:

$$
\omega_{1}^{2}=\frac{1}{m}\left[\left(\frac{n \pi}{L}\right)^{4}\left(E_{b}-\frac{N}{A_{b}}\right) I_{b}-\left(\frac{n \pi}{L}\right)^{2} N\right]
$$

being $E_{\mathrm{b}}$ and $I_{\mathrm{b}}$ the elastic modulus and the moment of inertia of the beam. Assuming $E_{\mathrm{b}}=26 \mathrm{GPa}$, $I_{b}=0.0054 \mathrm{~m}^{4}$ and $L=7.9 \mathrm{~m}$ the value of the first modal frequency $(n=1)$ is $13.84 \mathrm{~Hz}$ (fitting very well the experimental values reported in Figure 8: ) for all the values of the tension force $N$.

It must be noted that in equation (3) the terms containing the axial force $N$ are negligible with respect to the others (between $0.36 \%$ and $1 \%$ with respect to the others depending on the value of $N$ ) and this confirms the experimental results that the modal frequency does not change with the tension in the cables.

This is in perfect agreement with previous experimental results [4], [5] showing that a variation of the modal frequency may occur only if the increase of the tension in the cables is able to close preexisting crack for a damaged beam or some micro cracks in the case of an externally non cracked beam, thus increasing the stiffness of the beam. 


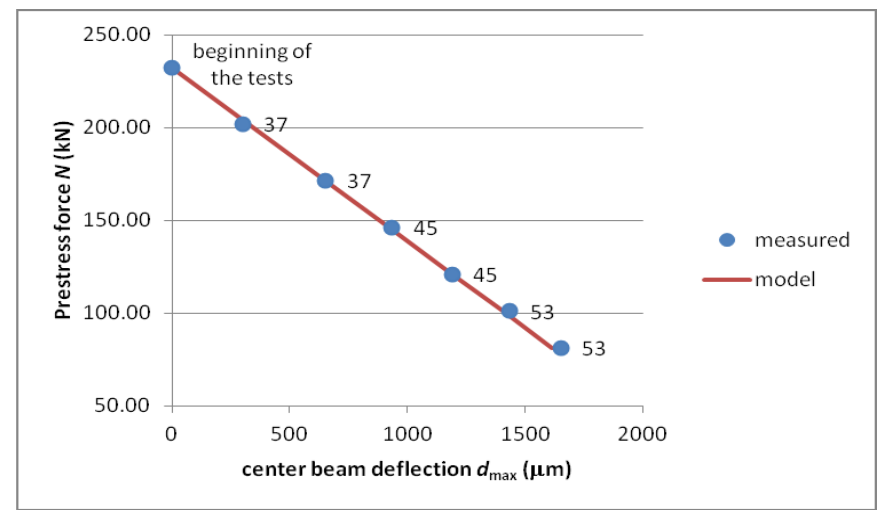

Figure 9: Center-span deflection vs prestress force $\mathrm{N}$

On the contrary, the values of the center-span deflection measured during this phase (T37, T45, T53 in Table 1 decrease linearly with the prestress force $N$, fitting very well the values given by the simple model of a supported beam under the dead load $q$ and the tension $N$ in the cables. It must be noted that each test includes the separate de-tensioning of the two cables so in Figure 9 the number of each test appears twice.

The deflections during the tests were measured assuming as a reference configuration the one under the dead load $q$ and the initial value of the prestress $\left(N_{\mathrm{o}}=232 \mathrm{kN}\right)$ : the center span deflection $d_{\max }$ reported in Figure 9 is thus the decrease of the deflection due to the reduction of the prestress load, with respect to the reference value at mid span:

$$
d_{\max }=\frac{e L^{2}}{8 E_{b} I_{b}}\left(N-N_{o}\right)
$$

A perfect fit of the results of these static tests is obtained assuming in equation (4) a value of the elastic modulus $E_{\mathrm{b}}$ of the concrete equal to $26 \mathrm{Gpa}$. This, as will be remarked in section 4 , is the same value that allows to calibrate the Finite Element model in order to match the values of the first three modal frequencies.

\subsubsection{Phase 2. Cracking at mid span}

In phase 2, following the cracking induced at mid-span during tests $\mathrm{S} 63$ and S73, a progressive reduction of the first modal frequency occurred. In Table 2 are reported the values of the first modal 
frequency estimated from sine-sweeps in the range $10-20 \mathrm{~Hz}$ with their relative variations with respect to the original frequency value $f_{0}$. The latter was estimated using data recorded during the last sine-sweep B55 on the undamaged beam.

The values in the last column quantify the damage in the beam during this phase. Immediately after the first cracking of the beam (occurred during test S63), the frequency shows a sharp reduction of about $6 \%$ with respect to the value in the undamaged configuration.

Table 2. Values of the first modal frequency during phase 2

\begin{tabular}{|c|c|c|}
\hline Test & $\begin{array}{l}\text { First modal frequency } f_{1} \\
{[\mathrm{~Hz}]}\end{array}$ & $\%{ }^{\left(f_{\mathrm{i}}-f_{0}\right) / f_{0}}$ \\
\hline B55 & $13.79 \quad\left(f_{0}\right)$ & \\
\hline B65 & 12.94 & -6.14 \\
\hline $\mathrm{B} 75$ & 12.72 & -7.75 \\
\hline $\mathrm{B} 82$ & 12.53 & -9.12 \\
\hline B88 & $12.35^{*}$ & -10.44 \\
\hline B95 & 12.24 & -11.22 \\
\hline B98 & 13.03 & +5.49 \\
\hline
\end{tabular}

After the second damaging test S73, a further (slight) reduction of frequency is noticed. The following static tests (S84-S86) produced a further and progressive reduction of frequency (up to test B95). This was likely to be due to the progressive increase in the cracks length as measured by the CODs installed on the beam at the crack locations. The same three point bending tests carried out on the undamaged beam (tests S27, S35, S36) had not induced any cracking or sensible reduction of frequency. It must be noted that the reduction of frequency between tests B82 and B88 is partially due to the reduction of the sweep rate which, during test B88 was lower than during the previous tests.

The increase in frequency recorded during test B98 can be explained by two circumstances.

First of all the variation in the mass distribution induced by the displacement of the shaker close (at $\mathrm{L} / 8$ ) to the left support. This altered the mass distribution on the beam causing, as already seen for phase 0 , an increase in the modal frequency. The Rayleigh ratio (see section 3.1.1) computed for tests B95 and B98 is equal to respectively $1.7 \%$ and $0.1 \%$ thus the displacement of the shaker in- 
duced a variation of the first modal frequency of $1.6 \% f_{0}$ that is about $0.23 \mathrm{~Hz}$. The second possible reason is that the displacement of the weight of the shaker from midspan may have allowed a partial closing of cracks close to this section. This seems to be confirmed by the measures of the CODs that, during test B98, did not record any opening of the cracks while during the previous sine sweep test B95 carried out with the shaker at midspan, several opening and closing of the cracks had been recorded. The increase of frequency between test B95 and the following test B98 shows thus the combined effect of the change in the mass distribution and of the crack closing after the removal of the weight of the shaker from the mid-span section.

\subsubsection{Phase 3. Tensioning of the upper cable}

In phase 3 the parabolic cable L2 was tensioned in two steps at $48 \mathrm{kN}$ and $120 \mathrm{kN}$ inducing a sharp increase in the modal frequency of about $10 \%$ between the two tests performed with the shaker at the same location: test S95 (before the tensioning of the cable L2, $f=12.24 \mathrm{~Hz}$ ) and test S103 (after the tensioning of the cable L2, $f=13.50 \mathrm{~Hz}$ ). This was likely to be due to the partial closing of the three cracks measured by the CODs. However the frequency did not recover its original value: a loss of about $2 \%$ with respect to the original frequency value was found and was probably due to a non complete closure of the cracks.

\subsubsection{Phase 4. Cracking of the 'repaired' beam}

In phase 4 the 'repaired' beam was again tested in three points bending tests (S113 and S122) by applying loads of increasing value at the section at $1 / 3 L$ from the left support, able to induce cracking at the loading section. Between and after these two cracking tests were performed sine sweep tests (B) As expected, a gradual decrease of the modal frequency was observed during the sinesweeps (see Figure 8: tests from 115 to 141). Further static tests (S132-S144) where carried out after the second cracking tests S122 keeping the loads below the value corresponding to the Service Limit Load. Nevertheless during the following sinesweeps further reductions of frequency were 
measured (tests B135, B140, B141). This, together with the measures of the COD, confirms the opening of the cracks during these tests and suggests that a progressive stiffness loss occurred in this phase, even for quite low values of the applied forces. Compared to phase 2 a lower loss of frequency occurs probably due to the higher tension force acting on the beam that retrained the opening and closing of the cracks during vibrations.

\subsubsection{Comparison with the variation of the second modal frequency}

In Errore. L'origine riferimento non è stata trovata. is reported the comparison between the first $f_{1}$ and second $f_{2}$ modal frequencies retrieved form sine sweep tests (B). The values of the frequency of the third mode computed using different accelerometers present a high variability, in some cases higher than the variation induced by the cracking of the beam so it is not possible to retrieve reliable information from the variation of the third modal frequency. The values computed for the first modal frequency are always the same whatever the response used for their identification. For the second modal frequency the variability of the identified values is slightly higher; in the figure are reported the mean of the values identified using all the accelerometers A1 to A8 (see Figure 4) deployed on the beam. Both values of frequency are affected by the displacements of the mass of the shaker from $\mathrm{L} / 4$ to $\mathrm{L} / 8$ from the left support (the term $m_{S} v\left(x_{S}\right)$ in equation (1) decreases for both modes). Also the displacement of the mass from $\mathrm{L} / 2$ to $\mathrm{L} / 8$ occurred before test 98 , affects both the modal frequencies (see test 98 for the first mode and 99 for the second mode) but in opposite senses consistently with the fact that moving the mass from $\mathrm{L} / 2$ to $\mathrm{L} / 8$ corresponds to an increase of the term $m_{S} v\left(x_{S}\right)$ for the second mode and to a decrease of this term for the first mode. 


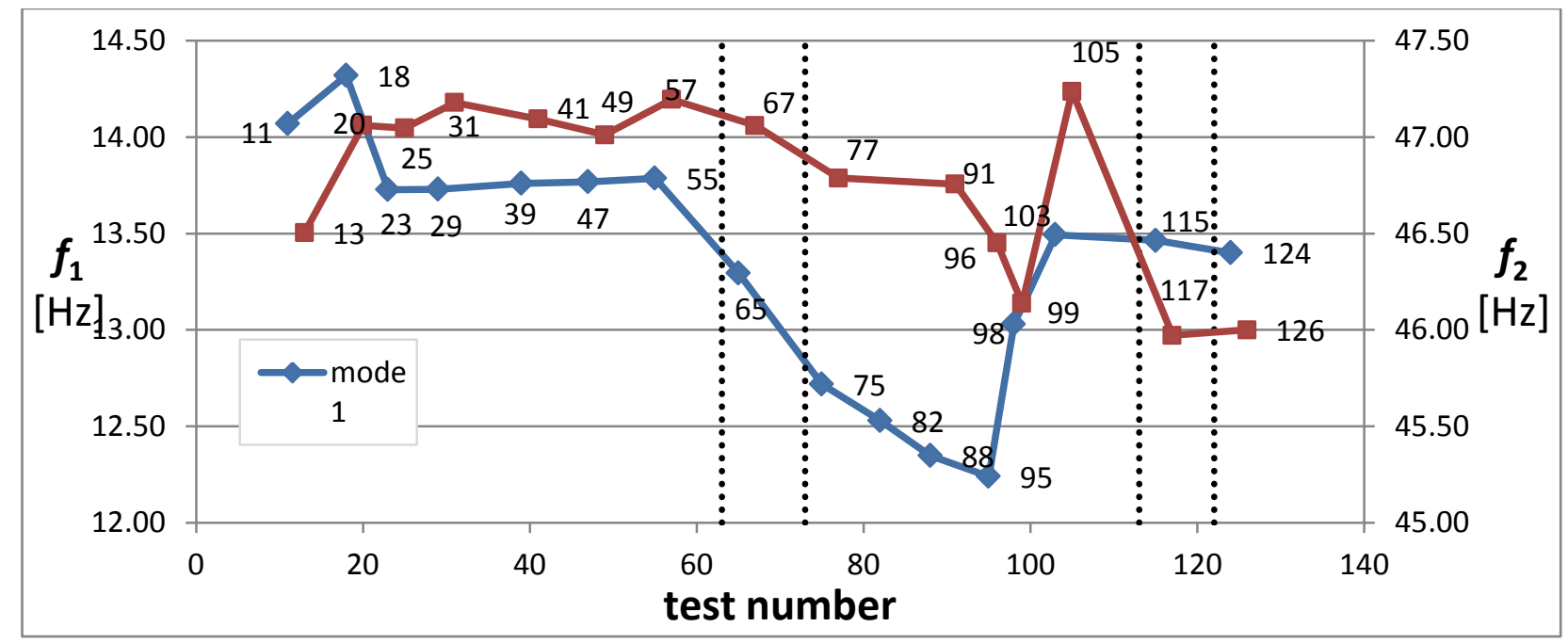

Figure 10: Variation of the first and second modal frequencies throughout the sequence of tests

The percentage variation of the two modal frequencies is also very different and this seems to confirm the interpretation given in section 3.1.3 for the increase of the first modal frequency during test 98 and based on the closing of the cracks at midspan induced by the displacement of the mass to the section at $\mathrm{L} / 8$. The second mode has a node at midspan so the closing of the cracks in this section have a very limited impact on the value of the second modal frequency.

This opposite trend of the two modal frequencies suggests that the existence of pre-existing cracks could be possibly detected comparing their values under different loading conditions inducing or not inducing the opening of the cracks.

The detensioning of the cables does not affect sensibly the second mode (see tests from 41 to 57 ) and the cracking at midspan affect the second modal frequency much less than the first one.

The 'repair intervention' that is the tensioning of cable L2 increases the values of both frequencies (see tests 103 and 105).

The cracking at L/3 induces a reduction of the second modal frequency percentually higher with respect to the one of the first mode. 


\subsection{Evolution of the bending stiffness with damage}

In Figure 11 to Figure 13 are reported the force-displacement diagrams for all the static tests performed on the beam. The beam exhibit an almost linear behaviour in all tests except those inducing cracks at midspan during phase 2 and at L/3 during phase 4 .

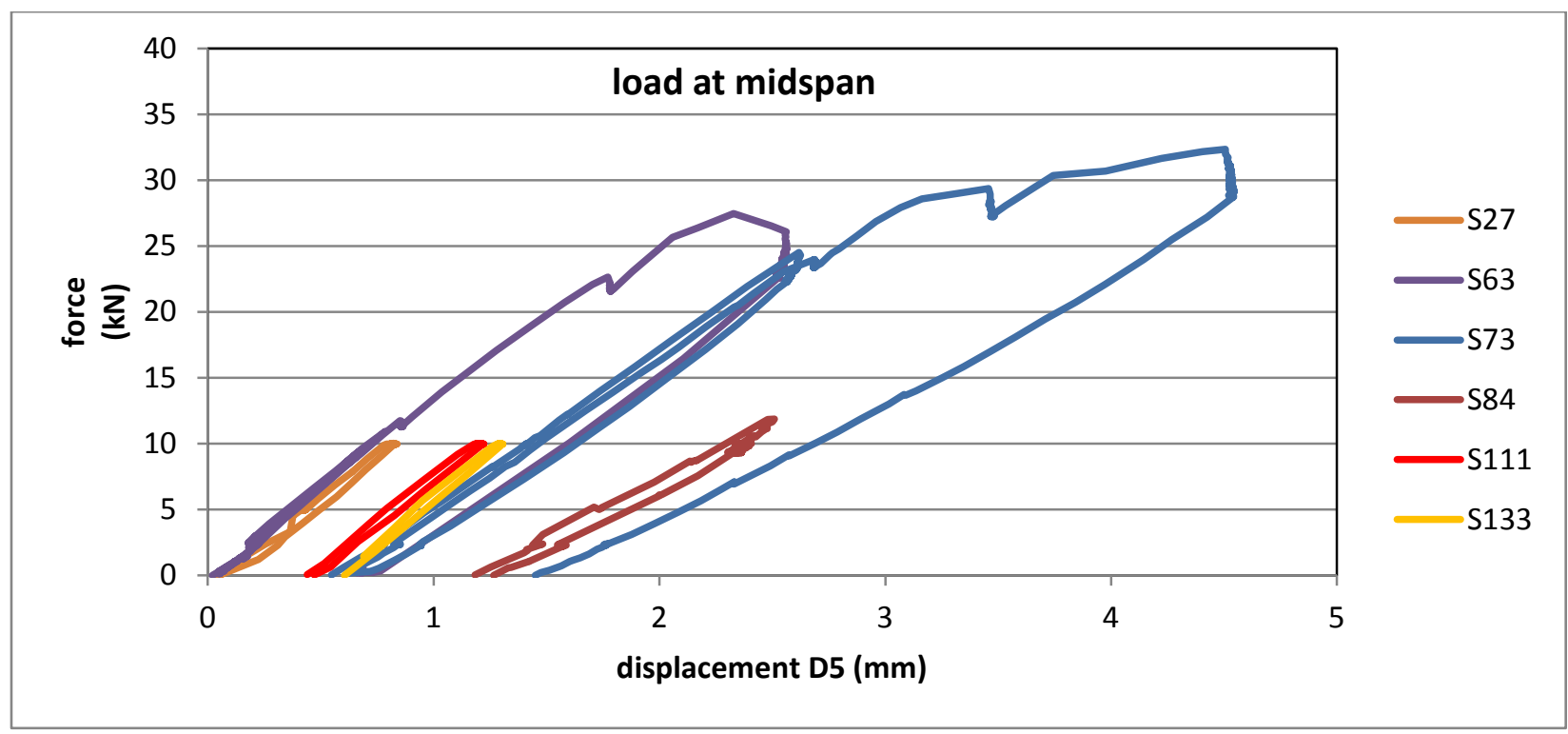

Figure 11: Force-displacement curves for the static tests with load applied at midspan

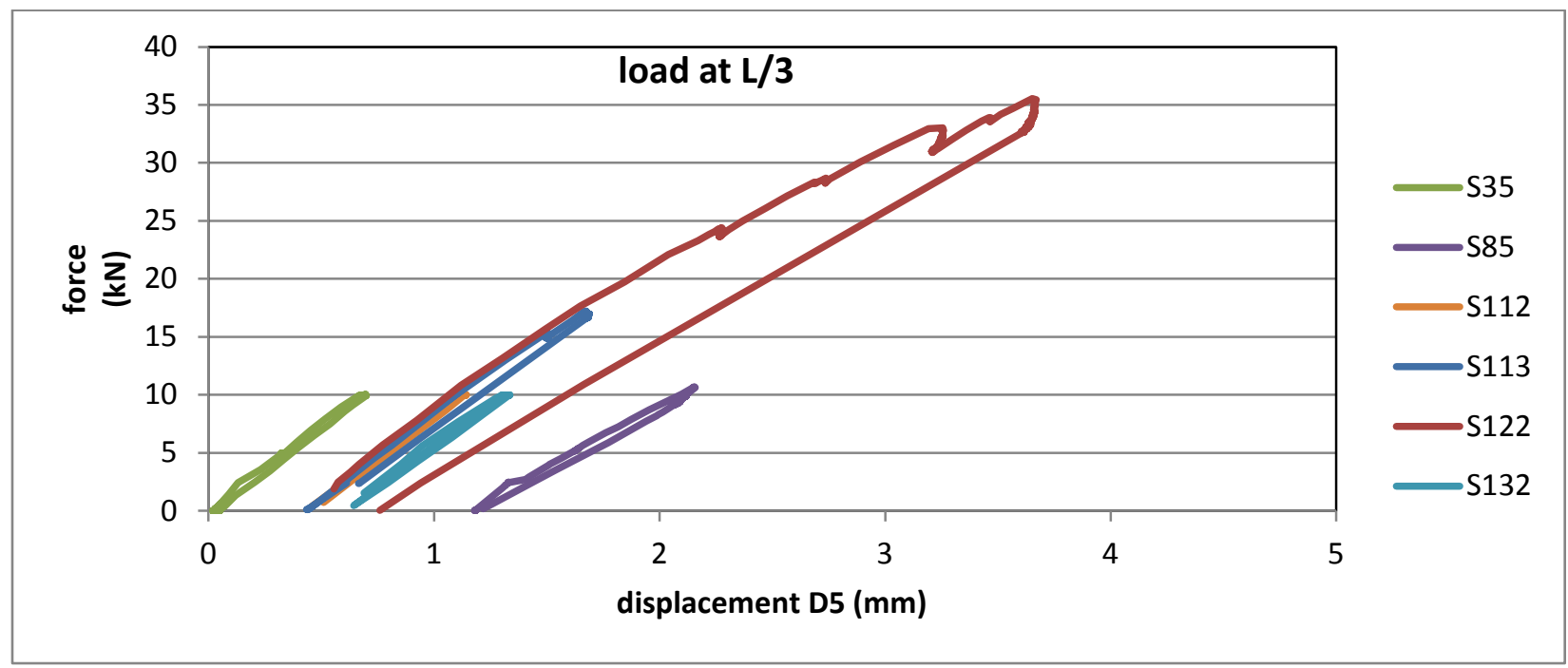

Figure 12: Force-displacement curves for the static tests with load applied at L/3 


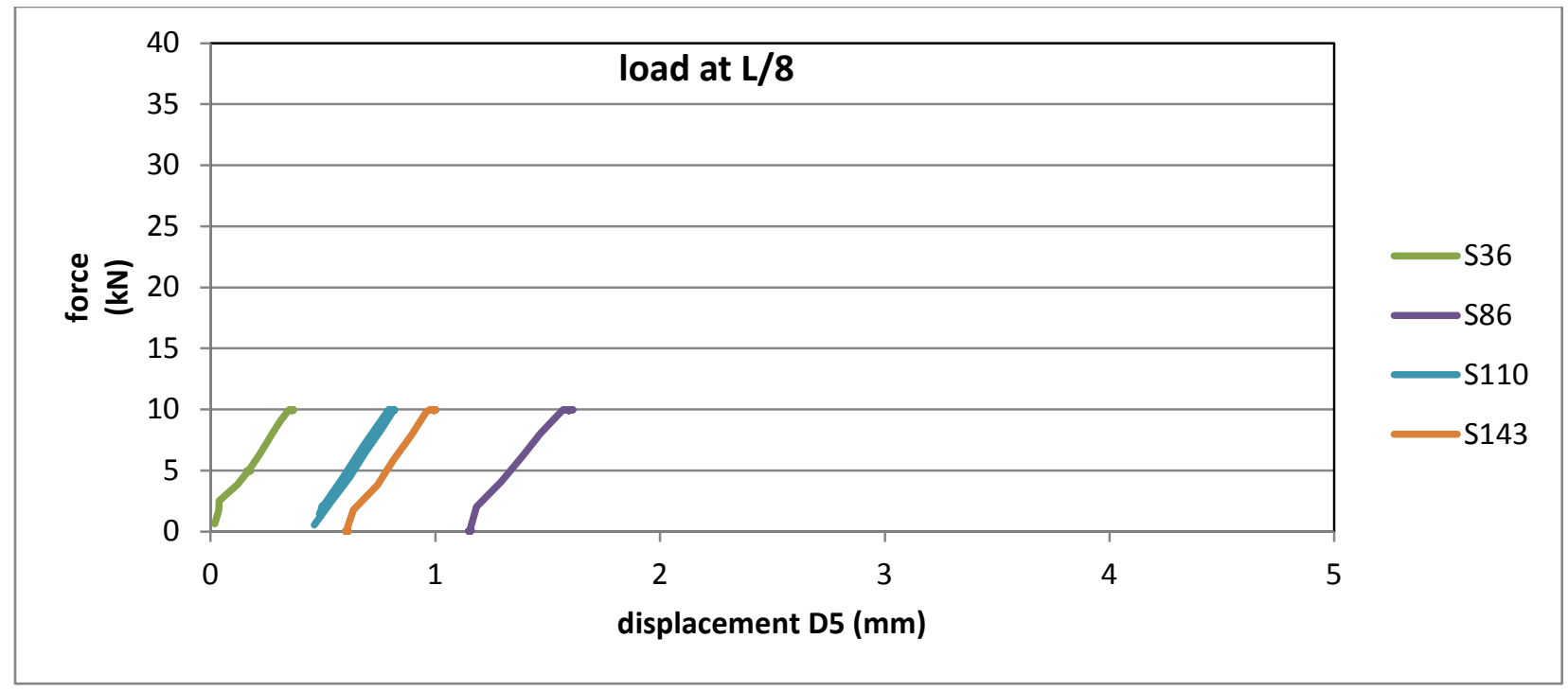

Figure 13: Force-displacement curves for the static tests with load applied at L/8

For each test the bending stiffness has been calculated as the slope of the best-fitting line of the unloading path. In Figure 14 the variation of the three values of the bending stiffness for different locations of the applied loads (see Figure 15) are reported.

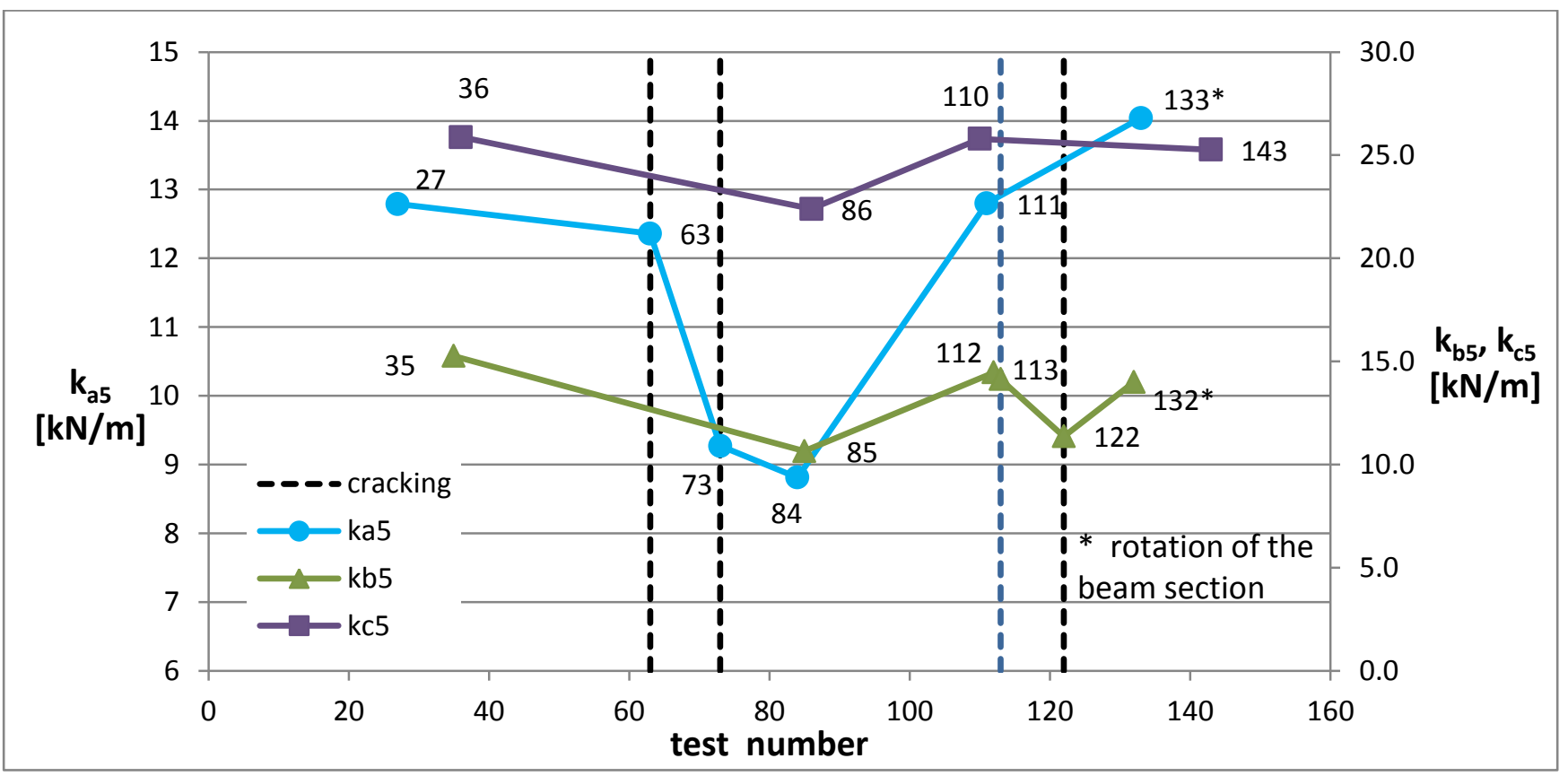

Figure 14: Variation of the bending stiffness from static tests

Specifically the values $\mathrm{k}_{\mathrm{a} 5}, \mathrm{k}_{\mathrm{b} 5}$ and $\mathrm{k}_{\mathrm{c} 5}$ have been calculated considering the displacement at point DI5 (see Figure 5) and the force applied at locations a) at mid-span; b) at 1/3 of the beam length from the left support and c) at 7/8 of the beam length from the left support (see Figure 15). 


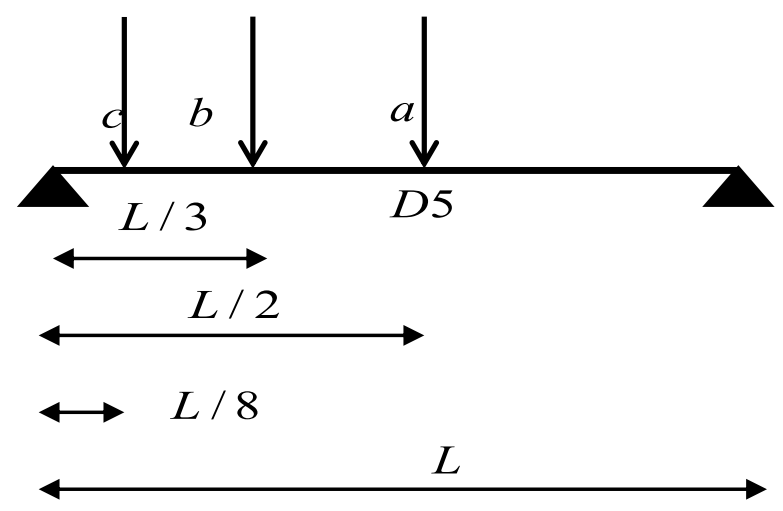

Figure 15: Locations of applied load for the definition of the bending stiffness

The evolution of the secant stiffness is consistent with that of the first modal frequency and specifically the cracking of the beam at mid span (phase 2) and at L/3 from the left support (phase 4) induces a reduction of the three values of the secant stiffness.

As a general comment the sensitivity to damage of the secant stiffness decreases with the distance between the applied load and the damaged section.

In Phase 2 (cracking at mid-span) the parameter most sensitive to damage is $\mathrm{k}_{5 \mathrm{a}}$ that is the secant stiffness at the cracked section: $\mathrm{k}_{5 \mathrm{~b}}$ and $\mathrm{k}_{5 \mathrm{c}}$ exhibit much lower decreases. After 'repairs' carried out in phase 3 , the beam recovers completely its original secant stiffness.

In phase 4 a limited number of points are available that do not allow to precisely follow the evolution of all the three values of the secant stiffness.

The cracking occurred at $1 / 3$ of the span length in phase 4 induces a significant reduction of $k_{5 b}$ (see tests S113 and S122). For the other two values secant stiffness ( $\mathrm{k}_{5 \mathrm{a}}$ and $\left.\mathrm{k}_{5 \mathrm{~b}}\right)$ no values are available before test S132 so it was not possible to investigate the single out the effect of cracking on these two values. Starting from test S132 an increase of the three values of stiffness is found; it can be explained by the rigid rotation of the cross section of the beam around its longitudinal axis.

Infact, starting from test S132, the cross section of the beam underwent a rigid rotation around its longitudinal axis of about $0.03^{\circ}$. This was estimated basing on the measures of the two displacement transducers DI5 and DI5bis shown in Figure 6. This rotation caused a rigid upward displacement of point 5 (a negative value was recorded by the sensor at this location). As a consequence a 
lower value of the displacement (with respect to that due to bending) occurred at point DI5, leading to an increase of the values of the secant stiffnesses $k_{5 a}, k_{5 b}$. For the stiffness $k_{5 c}$ this effect is not visible because in phase 4 the only test performed with the force applied at location c was test number S143 which was carried out when both the cracking and the rigid rotation of the beam had already occurred. A similar trend would have been found for $\mathrm{k}_{5 \mathrm{~b}}$ if the data from tests $\mathrm{S} 113, \mathrm{~S} 122$, and S133 would have not been available.

\subsection{Correlation between static and dynamic tests}

The analysis carried out in the previous section showed that there is a correspondence between the results of the static and dynamic tests.

A direct correlation among the two sets of results, in terms for example of frequencies from the dynamic tests and stiffnesses form the static tests is tricky because the two parameters are retrieved from different tests carried out in different moments.

The variation of the two parameters during the sequence of tests is reported in Figure 16. For the first modal frequency both the values retrieved from sine sweep tests and those calculated from hammer tests data are reported.

The comparison shows that:

1. in phase 2, during and after the cracking at mid-span, both the stiffness and the frequency exhibit a decreasing common trend. Results from sine sweeps allow to follow more accurately the variations due to the higher number of samples.

2. during Phase 3 no hammer tests were carried out, hence the only possible comparison is between stiffness and the frequency retrieved from the sine-sweeps tests. Both the value of the frequency and of the stiffness increase with respect to the minimum value attained during Phase 2 , but the variation of the stiffness is higher. Furthermore while the frequency from the sine sweeps, at the end of Phase 3 , show a decrease $(13.33 \mathrm{~Hz}$ for test 135$)$ with respect to its initial value $(13.74 \mathrm{~Hz}$ 
for test n. 23), an complete recover of the bending stiffness seems to occur $(12.8 \mathrm{kN} / \mathrm{m}$ during test $110 \mathrm{vs} 12.8 \mathrm{kN} / \mathrm{m}$ for test 27$)$.

3. In phase 4 , after repair and further cracking at $L / 3$, both values of $f_{1}$ from sine sweep and hammer tests show a reduction with respect to the value corresponding to the undamaged configuration. On the contrary the stiffness exhibits an increase for the static test 132 but, as already remarked in section 3.2, this value is unreliable and due to the rotation of the cross section around its axes.

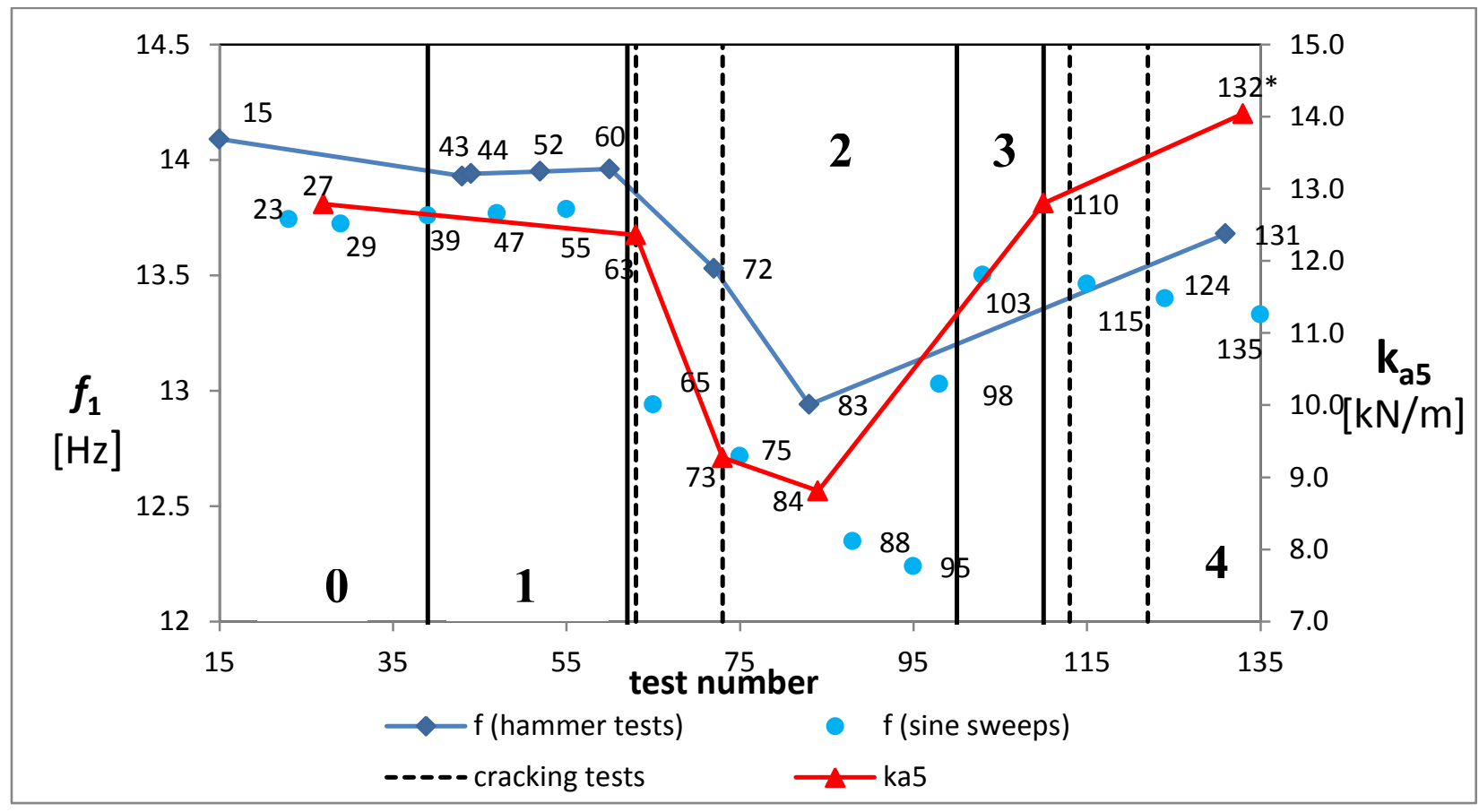

Figure 16: Variation of the first modal frequency and of the bending stiffness

\section{FE MODELLING AND MODEL TUNING}

The values of the first three modal frequencies recovered by sine sweep B39 and hammer test M43 are reported in Table 3. The three modes correspond to the first three vertical flexural modes. Due to the locations and to the sensing direction of the acceleration transducers, the lateral flexural modes and the torsional modes were not measured. A Finite Element linear model of the beam was built basing on the geometry of the specimen and updated using the experimental values of the first 
3 modal frequencies. The model was formulated under the following assumptions:

- three nodes elements were used to model the concrete;

- a weight per unit volume of $24 \mathrm{kN} / \mathrm{m}^{3}$ was assumed for the concrete;

- the Poisson ratio of the concrete was assumed equal to 0.275

- initially the boundary conditions were simulated as elastic using vertical and horizontal translational springs whose stiffness was calculated as a function of the mechanical characteristics of the rubber supports of the specimen.

A preliminary modal analysis was carried out assuming a tentative value of the elastic modulus of $29 \mathrm{GPa}$ in order to check the agreement between the modal parameters given by the FE model and the experimental ones. A manual tuning of the parameters of the model (elastic modulus and springs stiffness) was then performed to improve the fitting of the experimental modal frequencies: the best agreement was found assuming fixed supports at the ends of the beam and a value of $E_{\mathrm{b}}=26 \mathrm{GPa}$. This value is in perfect agreement with the results of the interpretation of the static tests reported in section 3.1.2. In Table 3 is reported the comparison between the modal frequencies recovered from the experimental tests (sine sweeps and impact) on the undamaged beam and the FE model.

Table 3. Modal frequencies of the undamaged beam

\begin{tabular}{cccc}
\hline Mode & \multicolumn{3}{c}{ Modal frequency $f$} \\
& \multicolumn{3}{c}{$[\mathrm{Hz}]$} \\
\hline & Sine & Impact test & FE mod- \\
& sweep & M43 & el \\
& B39 & & \\
\hline 1 & 13.8 & 13.9 & 13.9 \\
\hline 2 & 47.8 & 46.9 & 47.8 \\
\hline 3 & 128.6 & 127.6 & 120.3
\end{tabular}




\section{CONCLUDING REMARKS}

In this paper the results of an experimental campaign carried out on a scaled model of a posttensioned reinforced concrete beam have been presented. The effect of different test setup and types of testing, of the cracking and of the de-tensioning of the cables have been analyzed by following the evolution of the first modal frequency of the specimen during the sequence of tests and also in terms of the bending stiffness from the static tests. The correlation between the results of static and dynamic tests has been studied by comparing the evolution of the first modal frequency and the bending stiffness of the beam during the different phases of testing.

Results show that:

- testing conditions and specifically mass distribution and sweep rate can induce variations of the first modal frequency of the same order of magnitude of damage due to cracking;

- variations of the first and second modal frequencies with the tension in the prestressing cables are hardly detectable unless the latter induces a variation of the cracks state (open vs close) hence these parameters cannot be reliably used to detect prestress losses;

- the first modal frequency estimated from dynamic tests and the bending stiffness obtained from static tests are both sensitive to the cracking of concrete hence can be reliably used as concrete damage indicators.

the comparison of the effect of different loading conditions on different modal frequencies can allow to detect the existence of closed cracks;

- a close correlation exists between the results of the static and dynamic tests in terms of evolution of damage. However the dynamic tests show a higher sensitivity in detecting residual damage due to an incomplete closing of existing cracks: the closing of the cracks caused by the increase of tension in the cables does not allow a complete recover of the original value of frequency. On the contrary the bending stiffness can completely recover the original value thus hampering a correct detection of the residual damage. 
Table 4. Static and Dynamic tests performed on the beam

\begin{tabular}{|c|c|c|}
\hline \multirow{6}{*}{$\begin{array}{l}\text { Phase } 0 \\
\text { undamaged } \\
\text { beam }\end{array}$} & B10-B14 & Linear sine sweep. Shaker at 1/4L from the left support \\
\hline & M 15 & Hammer test \\
\hline & B $16-B 26$ & $\begin{array}{l}\text { Linear sine sweep. Shaker at L/8 from the left support (16-21) and at the mid span (22- } \\
\text { 26) }\end{array}$ \\
\hline & $\mathrm{S} 27$ & Static test. Load at mid span up to $10 \mathrm{kN}$ \\
\hline & B 28-B34 & Linear sine sweep. Shaker at $3 / 4 \mathrm{~L}$ from the left support \\
\hline & S35-S36 & Static test. Point load up to $10 \mathrm{kN}$ at $\mathrm{L} / 3$ from the left support and close to the left support \\
\hline \multirow{11}{*}{$\begin{array}{l}\text { Phase 1: } \\
\text { detensioning } \\
\text { of the bottom } \\
\text { cables }\end{array}$} & $\mathrm{T} 37$ & Detensioning of the bottom cables from about $120 \mathrm{kN}$ to about $40 \mathrm{kN}$ each \\
\hline & B38-B42 & Linear sine sweep tests \\
\hline & M43-M44 & Hammer tests. \\
\hline & T45 & Detensioning up to $61 \mathrm{kN}$ \\
\hline & B46-B51 & Linear sine sweep tests \\
\hline & M52 & Hammer test \\
\hline & T53 & Detensioning up to $40 \mathrm{kN}$ \\
\hline & B54-B59 & Linear sine sweep tests \\
\hline & M 60 & Hammer test. \\
\hline & BG 61 & Logarithmic sine sweep $(5-200 \mathrm{~Hz})$ \\
\hline & BL 62 & Linear sine sweep $(5-200 \mathrm{~Hz})$ \\
\hline \multirow{9}{*}{$\begin{array}{l}\text { Phase 2: } \\
\text { cracking at the } \\
\text { mid-span }\end{array}$} & S63 & Static test. Load at mid span up to $3 \mathrm{~mm}$ max deflection \\
\hline & B64-B71 & Linear sine sweep (64-69), linear and logarithmic sine sweep 5-200Hz (70-71) \\
\hline & M72 & Hammer test. \\
\hline & S73 & Static test. Load at mid span in 3 steps up to $5 \mathrm{~mm}$ max deflection \\
\hline & B74-B82 & Linear sine sweep $(74-79,82)$, linear and logarithmic sine sweep $5-200 \mathrm{~Hz}(80-81)$ \\
\hline & M83 & Hammer test. \\
\hline & S84-S86 & $\begin{array}{l}\text { Static test. Point load } 10 \mathrm{kN} \text { at mid span, at } 1 / 3 \mathrm{~L} \text { from the left support, at } \mathrm{L} / 8 \text { from the left } \\
\text { support. }\end{array}$ \\
\hline & B87-B97 & Linear sine sweep $(87-92,95-97)$, linear and logarithmic sine sweep 5-200Hz (93-94) \\
\hline & B98-B100 & Linear sine sweep. Shaker at L/8 from the left support. \\
\hline \multirow{2}{*}{$\begin{array}{l}\text { Phase 3: } \\
\text { tensioning of } \\
\text { the upper ca- } \\
\text { ble }\end{array}$} & T101 & Tensioning of the upper cable in 2 steps $48 \mathrm{kN}$ and $120 \mathrm{kN}$ \\
\hline & $\begin{array}{l}\text { B102-B109 } \\
\text { S110-S112 }\end{array}$ & $\begin{array}{l}\text { Linear sine sweep }(102-107) \text {, linear and logarithmic sine sweep } 5-200 \mathrm{~Hz}(108-109) \\
\text { Static test. Load } 10 \mathrm{kN} \text { at mid span, at } 1 / 3 \mathrm{~L} \text { from the left support, at } \mathrm{L} / 8 \text { from the left } \\
\text { support }\end{array}$ \\
\hline \multirow{7}{*}{$\begin{array}{l}\text { Phase 4: } \\
\text { cracking of the } \\
\text { repaired beam }\end{array}$} & S113 & Static test. Load at $1 / 3$ from the left support up to $1.3 \mathrm{~mm}$ max deflection \\
\hline & B114-B121 & Linear sine sweep (114-119), linear and logarithmic sine sweep 5-200Hz (120-121) \\
\hline & $\mathrm{S} 122$ & Static test. Load at $1 / 3$ from the left support up to $3.5 \mathrm{~mm}$ \\
\hline & B123-B130 & Linear sine sweep (123-128), linear and logarithmic sine sweep 5-200Hz (129-130) \\
\hline & M131 & Hammer test. \\
\hline & S132-S133 & Static test. Load $10 \mathrm{kN}$ at mid span (132), at 1/3 from the left support (133) \\
\hline & B134-B141 & $\begin{array}{l}\text { Linear sine sweep (134-139), linear and logarithmic sine sweep } 5-200 \mathrm{~Hz}(140-141) \\
\text { Static test. Load } 10 \mathrm{kN} \text { at } 1 / 3 \text { from the right support, at L/8 from the left support, at L/8 } \\
\text { from the right support. }\end{array}$ \\
\hline
\end{tabular}




\section{AKNOWLEDGEMENTS}

This research was supported by Conseil Régional d'Ile de France. This work was conducted as part of the project "SIPRIS", which involves several partner: Advitam (Vinci), ASF (Highways of the South of France), CEDRAT, ESIEE Paris, NECS, SYROKKO and IFSTTAR.

\section{REFERENCES}

[1] Kim J.T., Yun C.B., Ryu YS, Choi H.M. (2003). "Identification of prestress-loss in PSC beams using modal information”. Struct Eng Mech, 17 (3-4) (2003), pp. 467-482.

[2]Kato, M. and Shimada, S. (1986) "Vibration of PC Bridge During Failure Process.” Journal of Structural Engineering ASCE 112(7) p. 1692-1703.

[3]Unger, J., Teughels, A., and De Roeck, G. (2006). "System Identification and Damage Detection of a Prestressed Concrete Beam”. J. Struct. Eng., 132(11), 1691-1698.

[4]Jacobs, S., De Roeck, G. (2003). « Dynamic testing of a pre-stressed concrete beam”. 6th National Congress on Theoretical and Applied Mechanics, May, 2003.

[5]Saiidi, M., Douglas, B., and Feng, S. (1994). "Prestress Force Effect on Vibration Frequency of Concrete Bridges. ”J. Struct. Eng., 120(7), 2233-2241.

[6] Clough R.W., Penzien J. (1993). "Dynamic of Structures”. McGrawHill. Civil Engineering Series.

[7]Di Evangelista A., De Leonardis A., Valente C., Zuccarino L. (2011). "Design and testing of corrosion damaged prestressed concrete joists: the Pescara Benchmark". Journal of Physics: Conference Series, 305(1).

[8]Capozucca, R. (2008). "Detection of damage due to corrosion in prestressed RC beams by static and dynamic tests, ” J. Constr. Build. Mater., 22:738-746.

[9]Ta-Heng W., Ran H., Tz-Wei W. (2013). “The variation of flexural rigidity for post-tensioned 
prestressed concrete beams". Journal of Marine Science and Technology, Vol. 21, No. 3, pp. 300-308 DOI: 10.6119/JMST-012-0508-2.

[10] http://www.svibs.com

[11] Dall'Asta A., Dezi L. (1996). "Discussion on Prestress Force Effect on Vibration Frequency of Concrete Bridges. ” J. Struct. Eng. 458-459.

[12] Ewins D.L. (2000). "Modal testing: Theory, Practice and Application" - Second Edition. Research Studies Press Ltd.

[13] Girard A., Bugeat L.P., (2004). "Effect of sweep rate on modal parameters identification". Proc of the $5^{\text {th }}$ International Symposium on Envoronmental Testing for Space Programmes. Noordwijk, The Netherlands. (ESA SP-558, August 2004). 